\title{
Nonlinear analysis of longitudinal wave propagation in an axial rod with breathing crack (withdrawal notice)
}

Dhanashri Joglekar, Mira Mitra

Dhanashri M. Joglekar, Mira Mitra, "Nonlinear analysis of longitudinal wave propagation in an axial rod with breathing crack (withdrawal notice)," Proc. SPIE 9064, Health Monitoring of Structural and Biological Systems 2014, 90641K (9 March 2014); doi: 10.1117/12.2044999

Event: SPIE Smart Structures and Materials + Nondestructive Evaluation and Health Monitoring, 2014, San Diego, California, United States 


\section{Nonlinear analysis of longitudinal wave propagation in an axial rod with breathing crack (withdrawal notice)}

Proc. SPIE 9064, 90641K (2014); http://dx.doi.org/ 10.1117/12.2044999

Online Publication Date: 9 March 2014

Withdrawn from Publication: 15 May 2014

Conference Date: Sunday 10-13 March 2014

Conference Location: San Diego, California, United States

Conference Title:

Health Monitoring of Structural and Biological Systems 2014

Conference Chair: Tribikram Kundu

Dihanashri M. Joglekar, Mira Mitra

Indian Institute of Technology Bombay (India)

This paper has been withdrawn by the publisher because it was not presented at the conference. 